\title{
Vestibular function and quality of life in vestibular schwannoma: does size matter?
}

\section{Judith Nastjenka Wagner ${ }^{1}$ *, Miriam Glaser ${ }^{1}$, Berndt Wowra $^{2}$, Alexander Muacevic ${ }^{2}$, Roland Goldbrunner ${ }^{3}$, Christian Cnyrim ${ }^{4}$, Jörg-Christian Tonn ${ }^{5}$ and Michael Strupp ${ }^{1}$}

\author{
1 Department of Neurology, Ludwig-Maximilians University, Munich, Germany \\ 2 European CyberKnife Center, Munich, Germany \\ ${ }^{3}$ Department of Neurosurgery, University of Cologne, Cologne, Germany \\ ${ }^{4}$ Department of Neuroradiology, Kiel University, Kiel, Germany \\ ${ }^{5}$ Department of Neurosurgery, Ludwig-Maximilians University, Munich, Germany
}

\section{Edited by:}

Herman Kingma, Maastricht

University, Netherlands

\section{Reviewed by:}

Aasef G. Shaikh, Case Western

Reserve University, USA

Sergei B. Yakushin, Mount Sinai

School of Medicine, USA

*Correspondence:

Judith Nastjenka Wagner,

Department of Neurology,

Ludwig-Maximilians University,

Klinikum Grosshadern,

Marchioninistraße 15, D-81366

Munich, Germany.

e-mail: judith.wagner@med.unimuenchen.de

\begin{abstract}
Objectives: Patients with vestibular schwannoma (VS) frequently suffer from disabling vestibular symptoms. This prospective follow-up study evaluates vestibular and auditory function and impairment of quality of life due to vertigo, dizziness, and imbalance in patients with unilateral VS of different sizes before/after microsurgical or radiosurgical treatment. Methods:Thirty-eight patients with unilateralVS were included. Twenty-two received microsurgery, 16 CyberKnife radiosurgery. Two follow-ups took place after a median of 50 and 186.5 days. Patients received a standardized neuro-ophthalmological examination, electronystagmography with bithermal caloric testing, and pure-tone audiometry. Quality of life was evaluated with the Dizziness Handicap Inventory (DHI). Patient data was grouped and analyzed according to the size of the VS (group 1: $<20 \mathrm{~mm}$ vs group 2: $\geq 20 \mathrm{~mm}$ ). Results: In group 1, the median loss of vestibular function was $+10.5 \%$ as calculated by Jongkees Formula (range -43 to +52 ; group 2: median $+36 \%$, range -56 to +90 ). The median change of $\mathrm{DHI}$ scores was -9 in group 1 (range -68 to 30 ) and +2 in group 2 $(-54 ;+20)$. Median loss of hearing was $4 \mathrm{~dB}(-42 ; 93)$ in group 1 and $12 \mathrm{~dB}$ in group 2 (5; 42). Conclusion: Loss of vestibular function in VS clearly correlates with tumor size. However, loss of vestibular function was not strictly associated with a long-term deterioration of quality of life. This may be due to central compensation of vestibular deficits in long-standing large tumors. Loss of hearing before treatment was significantly influenced by the age of the patient but not by tumor size. At follow-up 1 and 2 , hearing was significantly influenced by the size of the VS and the manner of treatment.
\end{abstract}

Keywords: vestibular schwannoma, vertigo, microsurgery, CyberKnife

\section{INTRODUCTION}

Vestibular schwannoma (VS) is a benign tumor arising from the Schwann cells surrounding the vestibular nerve. With an annual incidence of 9.4/1,000,000, it is one of the more common benign intracranial tumors (Tos et al., 1992). VSs grow within the internal auditory canal and may extend into the cerebellopontine angle. Next to loss of hearing and tinnitus, dizziness, or unsteadiness of gait are common symptoms.

Vestibular deficits have been shown to severely affect quality of life (Pérez et al., 2003; Kammerlind et al., 2005). However, most patients with a chronic loss of vestibular function regain their balance due to the process of central vestibular compensation. Central vestibular compensation consists of multiple processes of perceptual, vestibulo-ocular, and vestibulo-spinal readjustment after unilateral and also bilateral vestibular loss. It has been shown to be rapid and mostly complete for static conditions. For dynamic conditions (i.e., associated with high-frequency head movements) it is often incomplete (for review see Brandt, 2000).

Treatment for VS is traditionally surgical. Due to technical improvements, the outcome has greatly improved since the first operation on a VS by Sir Charles Balance in 1894. However, the intervention is associated with potential risks including hearing loss, facial nerve palsy, brainstem/cerebellar injury, cerebrospinal fluid fistula, hydrocephalus, meningitis as well as with general risks associated with microsurgery and anesthesia (Tonn et al., 2000). Since the first reported case of a VS treated by radiosurgery, this approach has become a viable alternative to the microsurgical approach (Leksell, 1983; Delbrouck et al., 2003; Sughrue et al., 2009). Radiosurgery involves the single session application of a high single dose of radiation to a precisely controlled intracranial location, aiming to inhibit further tumor growth by inducing avascular necrosis (Mack et al., 2002; Hempel et al., 2006). Usually, hospitalization is not required with this method. However, it is not without risk, possible complications including injury of the facial or cochlear nerve, vertigo, hydrocephalus, headaches, and tinnitus (Mack et al., 2002; Delbrouck et al., 2003; Hayhurst et al., 2005).

Since the first prospective follow-up of vestibular morbidity after treatment for VS in 2006, multiple analyses of the functional outcome in these patients have been published (Pollock et al., 2006). However, only few studies were conducted in a prospective way (Myrseth et al., 2009). Furthermore, although vertigo, dizziness, and unsteadiness of gait are common symptoms 
of VS (reported incidence between 49 and 66\%), these symptoms were often only assessed in a qualitative or semi-quantitative way (El-Kashlan et al., 1998; Lynn et al., 1999; Heerma et al., 2000; Inoue et al., 2001; Humphriss et al., 2003).

We present a prospective pilot study on patients with VS of different sizes before and after radio- or microsurgical treatment. The influence of the tumor and the treatment on the function of the cranial nerves V, VII, VIII is investigated. The main focus of interest is on the investigation of the vestibular nerve function. We assess morbidity due to dizziness and unsteadiness of gait in two groups of patients - defined according to tumor size - using extensive vestibular testing and standardized testing for impairment of quality of life due to vertigo/imbalance. By comparing two groups of patients with VS who differ according to tumor size - and hence level of vestibular loss of function - we aim to elucidate the role of vestibular compensation on quality of life in unilateral vestibular disease.

\section{PATIENTS AND METHODS PATIENTS}

Thirty-eight patients (21 male, 17 female) with unilateral VS were included (median age 49 years, range 28-76). Twenty-two received microsurgery, 16 radiosurgery. Decision as to the treatment modality was made according to tumor size (largest diameter $>2.5 \mathrm{~cm}$ was an indication for microsurgery), patient preference, and diagnostic issues (i.e., in those cases, in which the diagnosis of VS was uncertain, microsurgery was preferred). Follow-ups took place after a median of 50 ( 33 patients) and 186.5 days ( 37 patients; some patients received the second follow-up only).

\section{ASSESSMENT OF TUMOR SIZE}

For tumor volumetry, the dose planning software (MultiPlan ${ }^{\mathrm{TM}}$ ) of the CK system is used. The tumor is outlined in every MRI slice resulting in a tumor region of interest (ROI). Then, multiplated by the slice thickness all ROIs are summed up to calculate the tumor volume.

\section{MICROSURGERY}

Surgery was performed with resection of the tumor via a retrosigmoidal craniectomy. During all phases of tumor dissection, electrophysiological neuromonitoring was performed by EMG for facial nerve function and BAEP for hearing function, provided there was preserved hearing preoperatively. After watertight closure of the dura, the craniectomy was sealed with bone cement.

\section{RADIOSURGERY}

All radiosurgical treatments were performed in an outpatient setting. The CyberKnife is a frameless, image-guided robotic radiosurgery system (Adler et al., 1997). The therapeutic radiation is generated by a small linear accelerator (linac) mounted on the robotic arm. A G3 and a G4 linac were used in this study. The dose rate $(6 \mathrm{MeV}$ Photon radiation) was $3 \mathrm{~Gy} / \mathrm{min}$ with the $\mathrm{G} 3$, and $6 \mathrm{~Gy} / \mathrm{min}$ with the G4. Treatment planning was performed with the Multiplan Software (Accuray Inc., Sunnyvale, CA, USA). Radiosurgery with the CyberKnife applies a non-coplanar, non-isocentric treatment plan, which allows the delivery of a homogeneous dose distribution with a steep dose gradient. The dose prescription for VS was 12.5 - 13 Gy at the tumor margin which corresponded to the $65-70 \%$ isodose.

\section{NEURO-OPHTHALMOLOGICAL AND -OTOLOGICAL EXAMINATION}

All patients underwent a full and standardized neuroophthalmological and -otological examination with special emphasis on spontaneous nystagmus with Frenzel's goggles in primary position, lateral and vertical gaze direction, gaze-evoked nystagmus, horizontal head impulse test, and determination of the subjective visual vertical (SVV).

\section{CLINICAL ASSESSMENT}

Patients were assessed as to the presence of vertigo/unsteadiness of gait, facial paresis, and hyp- or paraesthesia on the side of the face ipsilateral to the VS.

\section{ELECTRONYSTAGMOGRAPHY}

Bithermal caloric testing was performed in all patients. Water irrigation was performed for $30 \mathrm{~s}$ at $30^{\circ} \mathrm{C}$ for the cool irrigation and $44^{\circ} \mathrm{C}$ for the warm irrigation. The mean peak slow phase velocity (SPV) was determined with Igor Pro Wave Metric (version 3.13) software. Since there is a large intersubject variability of the nystagmus induced by caloric irrigation and a small intraindividual variability of the response of the right and the left labyrinth in healthy subjects, the Jongkees' "vestibular paresis formula": $\left(\left(\left(\mathrm{R} 30^{\circ}+\mathrm{R} 44^{\circ}\right)-\left(\mathrm{L} 30^{\circ}+\mathrm{L} 44^{\circ}\right)\right) /\left(\mathrm{R} 30^{\circ}+\mathrm{R} 44^{\circ}+\mathrm{L} 30^{\circ}+\mathrm{L} 44^{\circ}\right)\right) \times$ 100 , was used, where, for instance, $\mathrm{R} 30^{\circ}$ is the mean peak SPV during caloric irrigation with $30^{\circ} \mathrm{C}$ water (Jongkees et al., 1962). Absolute values were used to quantify (in percent) the unilateral weakness of the affected ear.

\section{AUDIOMETRY}

Patients received standard pure-tone audiometry. The mean auditory loss was calculated from loss of hearing $(\mathrm{dB})$ at 500, 1000, and $2000 \mathrm{~Hz}$

\section{ASSESSMENT OF QUALITY OF LIFE}

Impairment of quality of life by dizziness was evaluated with the Dizziness Handicap Inventory (DHI). The inventory consists of 25 questions pertaining to the impairment of quality of life by vertigo/imbalance. The maximum score is 100 , the minimum score 0 points (a high score indicating a greater impairment of quality of life by dizziness).

\section{STATISTICS}

The Stata/IC 11.1 software (Stata Corp. 4905 Lakeway Dr., College Station, TX 77845, USA) and Microsoft Excel was used for statistical analysis. Tumor size and vestibular function as measured by Jongkee's formula and DHI scores respectively were correlated using Spearman's correlation coefficient. Comparisons between the groups regarding tumor size, DHI scores, and vestibular function were evaluated using the $t$-test for independent samples. Analysis of variance (ANOVA/MANCOVA) and regression analysis was used to assess the influence of predictor variables (patient's sex and age, tumor side, tumor diameter, treatment method) on outcome variables (function of cranial nerves V, VII, VIII, especially the vestibular nerve function). Non-parametric statistical dependence between two variables was assessed by Spearman's 
rank correlation test. Two-group-proportion tests were performed to compare dichotomous variables before and after treatment. The differences in mean values were calculated with $t$-tests. A threshold of 0.05 was applied.

\section{ETHICS}

All methods used were approved by the local ethics committee.

\section{RESULTS}

Group 1 (VS $<20 \mathrm{~mm})$ comprised 21 patients, group 2 (VS $\geq 20 \mathrm{~mm}$ ) 18 patients. Patients in either group did not differ regarding age and gender (group 1: median age 46 years, 12 male; group 2: median age 52 years, 9 male). Due to selection criteria (i.e., smaller tumors were more often treated radiosurgically than large ones), patients in group 1 more frequently received CyberKnife treatment (14 patients), whereas in group 2, patients were more often treated microsurgically (16 patients).

\section{GROUP 1 (VS < 20 MM) \\ Vestibular function}

All patients received bithermal caloric testing at baseline, i.e., before treatment. Caloric testing was performed in 17 patients at the first and 19 patients at the second follow-up. At baseline, patients in this group had a median reduction of vestibular function of $38 \%$ (relative to unaffected side according to Jongkee's formula; range $6-100 \%$ ). The patients had a moderate deterioration of vestibular function $[52 \%(18 ; 100 \%)$ reduction at the first and $53 \%(9 ; 100 \%)$ at the second follow-up], resulting in a complete vestibular paresis in four patients (Figure 1).

\section{Neuro-ophthalmology findings}

In one patient, spontaneous nystagmus in primary position was detected on clinical examination before treatment. In this patient, spontaneous nystagmus persisted on the first follow-up and had disappeared by the second follow-up. In one patient without spontaneous nystagmus at baseline, spontaneous nystagmus was detected after treatment. Gaze-evoked nystagmus was present in five patients before treatment. In three of them, the nystagmus persisted after treatment, in the other two it had disappeared on the first follow-up. One other patient displayed gaze-evoked nystagmus after treatment. The head impulse test revealed a loss of the horizontal vestibulo-ocular reflex (VOR) on the affected side in 10 patients of this group before treatment. In an additional four patients the head impulse test became pathological after treatment. Mean deviation of the SVV increased slightly from $1.3^{\circ}$ at baseline to $1.6^{\circ}$ and $2.1^{\circ}$ at the first and second follow-up. However, this increase was not significant.

\section{Auditory function}

The median loss of hearing was $28 \mathrm{~dB}(12 ; 80)$ at baseline, $33 \mathrm{~dB}$ (8; deafness) at follow-up 1 and $37 \mathrm{~dB}$ (10; deafness) at follow-up 2.1 patient was deaf after treatment (microsurgery).

\section{Symptoms and other clinical findings}

Eighteen patients reported dizziness or unsteadiness of gait before radio-/microsurgery. In 17 of them, dizziness/unsteadiness was continuously present. Ten patients suffered from vertigo attacks.
Post-treatment, 14 patients complained of dizziness/unsteadiness of gait (in 13 of these, the symptoms had been present before the intervention), 2 patients had vertigo attacks. One of the patients had a transient facial paresis before treatment, none had a facial paresis after treatment. One patient reported facial paresthesia before and after treatment. In two patients, preexisting facial paresthesia disappeared after treatment, in another two patients, facial paresthesia first appeared after treatment.

\section{Quality of life}

The median DHI score at baseline was 32 in this group (range 068 ). At the first follow-up the median score was 26 , at the second follow-up 19. In the two patients with complete vestibular paresis, self estimation of quality of life by DHI deteriorated in two and slightly improved in the other two cases. Median change of DHI scores (baseline - last follow-up available) was $-9(-68 ; 30)$.

\section{GROUP 2 (VS $\geq 20$ MM) \\ Vestibular function}

In this group, one patient had a complete unilateral vestibular paresis before and 11 patients after treatment. Patients in this group deteriorated from a median vestibular reduction of function of $64 \%$ before treatment (range $0-100$ ) to $76 \%$ (first follow-up; range 60-100) and 100\% (second follow-up; range 7-100; Figure 2).

\section{Neuro-ophthalmology findings}

Only one patient in group 2 had spontaneous nystagmus in primary position before and after treatment (this patient had suffered a periprocedural cerebellar ischemia). None of the other patients developed spontaneous nystagmus post-treatment. Gaze-evoked nystagmus was present in eight patients before treatment. In five of these patients, the nystagmus persisted afterward. The head impulse test was pathological on the affected side in 11 patients before, and in 14 patients after treatment. Mean deviation of the SVV increased from $2.0^{\circ}$ at baseline to $2.2^{\circ}$ at the first follow-up and to $3.0^{\circ}$ at the second follow-up.

\section{Auditory function}

The median loss of hearing was $46 \mathrm{~dB}(10 ; 75)$ at baseline, $54 \mathrm{~dB}$ (15; deafness) at follow-up 1 and $59 \mathrm{~dB}$ (20; deafness) at follow-up 2. Eight patients were deaf after treatment (all microsurgery).

\section{Symptoms and other clinical findings}

Twelve patients reported dizziness or unsteadiness of gait at baseline, with four patients suffering from vertigo attacks. After treatment, 14 patients complained of dizziness/unsteadiness of gait, with 2 patients suffering from vertigo attacks. One of the patients had a facial paresis before and after treatment, another one had a transient facial paresis before treatment. One patient developed a persisting facial paresis after surgery. None of the patients reported facial hyp- or paresthesia before treatment. In four patients, this symptom appeared after microsurgery. One patient suffered a periprocedural right hemispheric cerebellar ischemia.

\section{Quality of life}

The median DHI score at baseline was 20 in this group (range $0-54)$. At the first follow-up the median score was 6 , at the second follow-up 22. Median change of DHI scores (baseline - last 


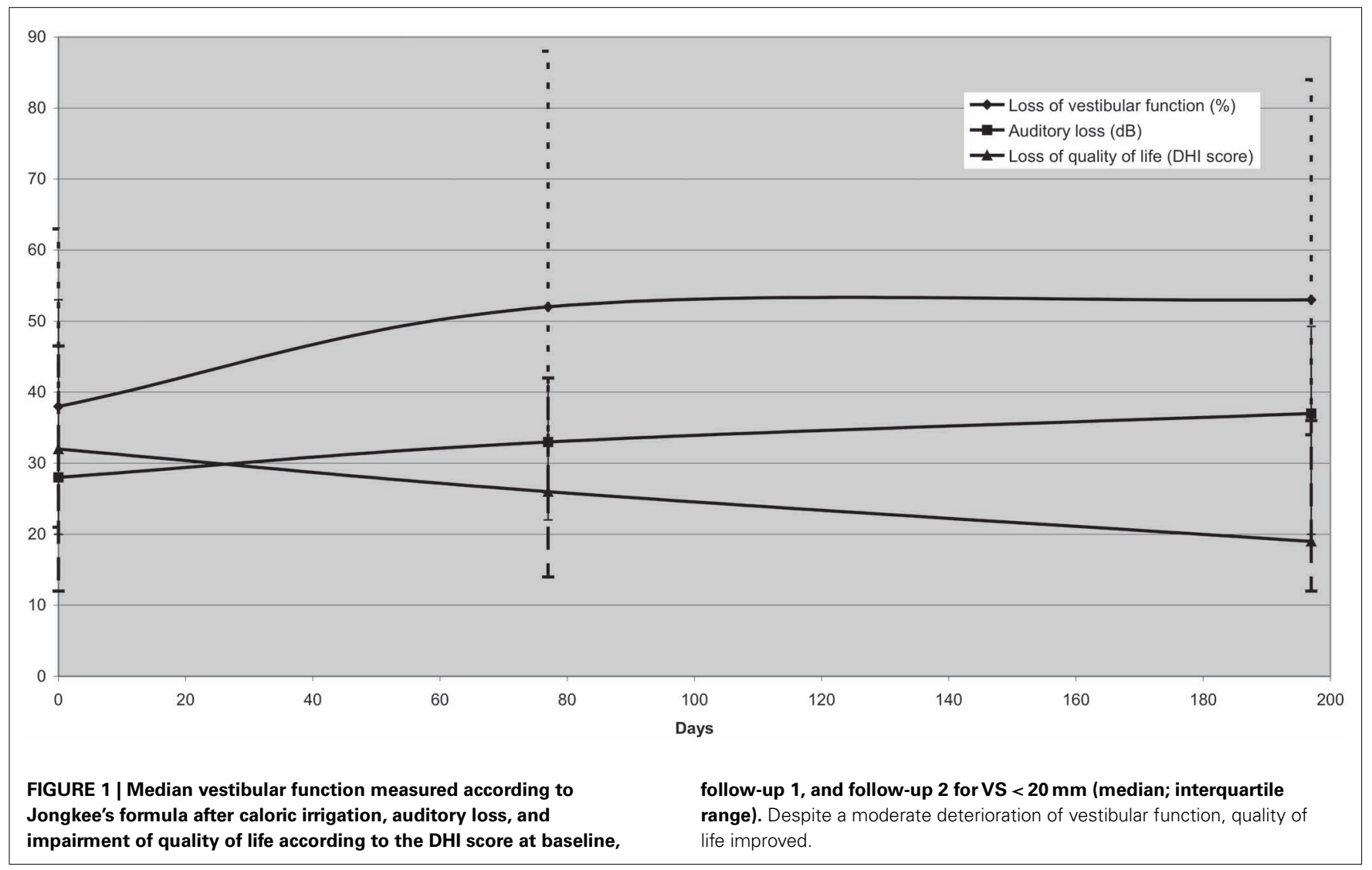

follow-up available) was +2 in (range -54 to +20 ). In those patients with measurable vestibular function at baseline who progressed to complete unilateral vestibular paresis, median DHI change was $+2(-32 ; 20)$. Evaluation of DHI scores at baseline or at the follow-ups revealed no correlation with tumor size in either group. The surprisingly low median DHI at the first followup may be due to confounding by the fact that those patients with severe symptoms were not available at the first follow-up as they were still in rehabilitative care.

\section{GROUP 1 VS. GROUP 2}

The different tumor sizes in the two groups are reflected in the higher degree of loss of vestibular function in group 2 before and after surgery $(64,76$, and $100 \%$ at baseline, first follow-up and second follow-up vs 38,52 , and $53 \%$ in group 1). DHI scores, reflecting the impairment of quality of life in the two groups, did not differ significantly at baseline and follow-up 2 (20, 6, and 22 at baseline, first follow-up and second follow-up vs 32, 26, and 19 in group 1). The majority of patients in each group complained about vertigo: $86 \% / 67 \%$ in group 1 and $67 \% / 78 \%$ in group 2 (before/after treatment). However, vertigo attacks were more frequent in patients with small VS before treatment $(48 \% / 10 \%$ in group 1 vs $22 \% / 11 \%$ in group 2 pre-/post-treatment). Facial and trigeminal dysfunction was encountered more frequently in group 2 , reflecting the larger size of the VS and the higher rate of microsurgical interventions in this group. The degree of loss of hearing before treatment was significantly influenced by the age of the patient $(p<0.001)$ but not by tumor size. At follow-up 1 and 2 , hearing was significantly worse in those patients with a large VS. Age was not a significant determinant for loss of hearing on the follow-up visits $(p<0.08)$.

\section{MICRO- VS RADIOSURGERY}

To complement comparison between patients grouped according to the size of their tumor, we also compared patients according to the method of treatment used. Follow-up intervals did not differ between patients treated with either technique [radiosurgery: median 62.5 days at follow-up $1(44 ; 117), 208$ days at follow-up 2 (166; 383); microsurgery: median 56.5 days $(30 ; 114)$ and 195 days $(117 ; 302)]$. Tumor size differed significantly $[p<0.00001$; mean $10.13 \mathrm{~mm}$ (radiosurgery) vs $23.64 \mathrm{~mm}$ (microsurgery)]. Whereas there was no significant loss of hearing after radiosurgery, microsurgery did alter hearing significantly $(p<0.001)$. Loss of vestibular function and impairment of quality of life (DHI) on follow-up 1 were more pronounced in the microsurgery group. This did not apply to follow-up 2. The method of treatment did not significantly influence the evolution of vestibular function between baseline and follow-up 2. Neither did the patients' sex or the size and side of the VS.

\section{DISCUSSION}

\section{AIM OF THE STUDY AND MAJOR FINDINGS}

The aim of this prospective study was to evaluate the effect of loss of vestibular function on quality of life in patients with VS of different sizes treated with micro- and radiosurgery. Whereas most 


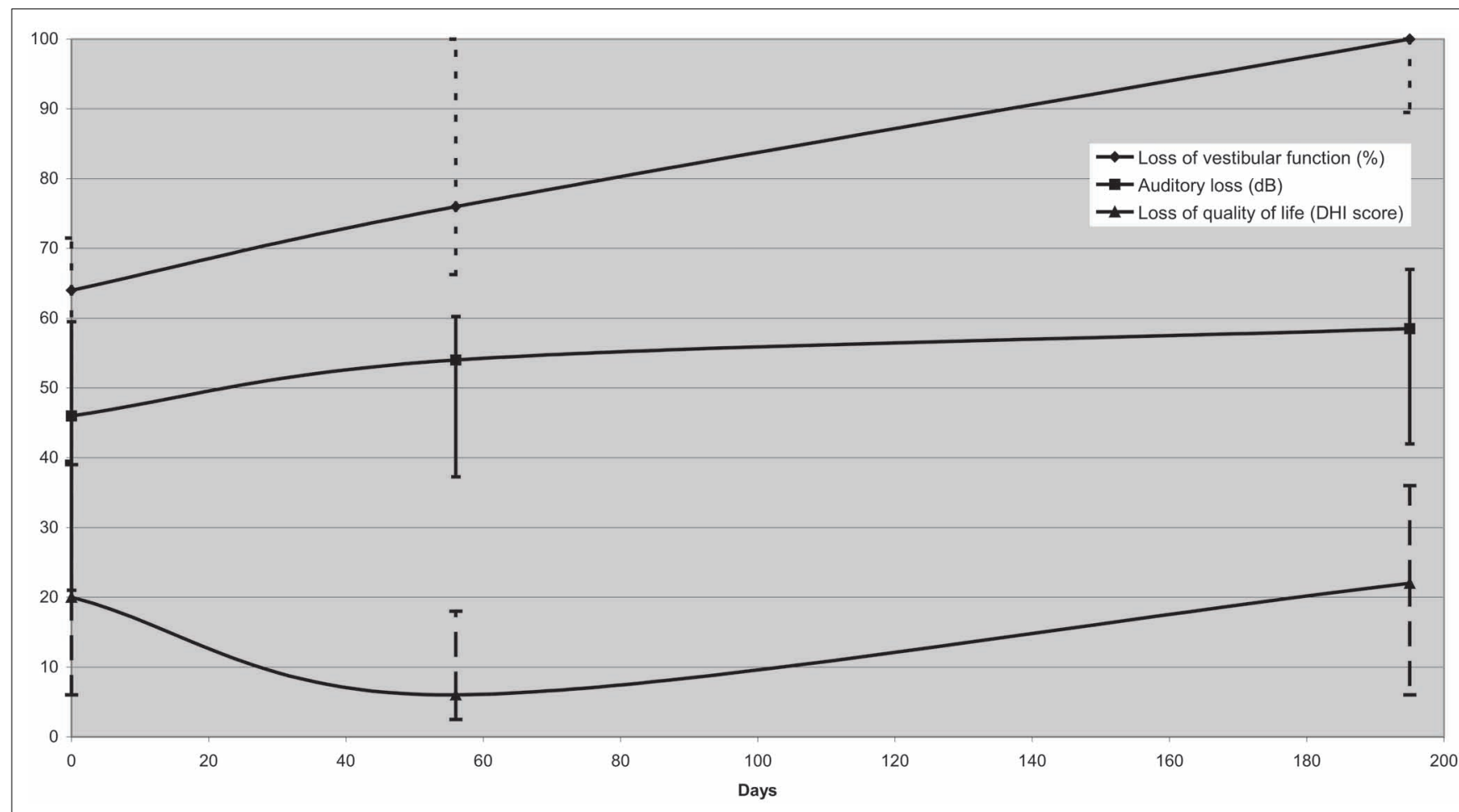

FIGURE 2 | Median vestibular function measured according to Jongkee's formula after caloric irrigation, auditory loss, and impairment of quality of life according to the DHI score at baseline, follow-up 1, and follow-up 2 for VS $\geq \mathbf{2 0 ~} \mathrm{mm}$ (median; interquartile range). Despite a marked deterioration of vestibular function, DHI scores remained relatively stable. previous studies relied on qualitative or semi-quantitative parameters to quantify dizziness, we documented vestibular function using electronystagmography with bithermal caloric testing and the head impulse test (Lynn et al., 1999; Darrouzet et al., 2004; Hempel et al., 2006). We also looked for central oculomotor and vestibular dysfunction by a standardized neuro-ophthalmological examination, as well as loss of auditory function and other cranial nerve disorders. Quality of life was assessed using the standardized DHI.

The results of this study allow drawing the following conclusions: loss of auditory function does not correlate with the size of the VS but with the method of treatment used. In contrast, the loss of vestibular function clearly correlates with the size of the schwannoma. In both groups (VS $<20 \mathrm{~mm}$ vs $\mathrm{VS} \geq 20 \mathrm{~mm}$ ), micro- and radiosurgery cause a further decrease of vestibular function. However, the degree of loss of vestibular function does not correlate with the impairment of activities of daily living due to vertigo.

\section{VERTIGO AND QUALITY OF LIFE IN LARGE VS}

Previous studies show that dizziness and unsteadiness of gait are common symptoms in patients with VS (Parving et al., 1992; Driscoll et al., 1998; Lynn et al., 1999; Inoue et al., 2001; Darrouzet et al., 2004). In our study, $64 \%$ of patients in group 2 complained of these symptoms before treatment. In this group, more than $50 \%$ of the patients suffered from complete vestibular paresis after micro-/radiosurgery as assessed by caloric testing and clinically by the head-thrust test. Nonetheless, DHI scores in this group were lower than in group 1 pre-treatment and remain relatively stable in the post-operative follow-up with a median progression of +2 .

A possible explanation for this effect is that due to the severe loss of vestibular function pre-treatment, central vestibular compensation has already occurred. The major neuronal change in the vestibular nuclei during central vestibular compensation appears to be the recovery of resting activity in the vestibular nuclei ipsilateral to the loss of peripheral vestibular input. There is also evidence from animal data that transcommissural synaptic input to the vestibular nuclei from the contralateral labyrinth increases in efficacy (Smith and Darlington, 1991; Curthoys and Halmagyi, 1999). Furthermore, visual compensation may contribute to central vestibular compensation to reduce balance deficits (Pyykkö et al., 1995).

\section{VERTIGO AND QUALITY OF LIFE IN SMALL VS}

As in group 2, most patients in group 1 reported subjective dizziness or unsteadiness of gait. Although the size of the VS and the degree of loss of vestibular function before treatment were significantly lower than in group 2, DHI scores were slightly - although not significantly - higher at baseline in this group. Whereas DHI scores in group 2 remain stable pre- and post-treatment, they drop by almost $40 \%$ after treatment in group 1 .

This may be due to two factors. First of all, steady growth of the neuroma with constant change in the vestibular input of the 
affected side renders central vestibular compensation more difficult compared to a scenario with complete - or almost completebut stable unilateral loss of vestibular function. Previous reports support the hypothesis that changes in vestibular function affect the quality of life more severely than the absolute degree of loss of function: a metaanalysis reports a higher incidence of vertigo in patients treated with low-dose gamma-knife radiation rather than a high-dose radiation (Sughrue et al., 2009). The authors claim that this may be due to a more complete dysfunction of the vestibular nerve in the high-dose group. Another study reports a higher incidence of pre-treatment vertigo in patients with small and medium-sized VSs as compared to large schwannomas ( $>4 \mathrm{~cm}$; Heerma et al., 2000). In a detailed description of the sensorimotor postural rearrangement after unilateral vestibular deafferentation in patients with VS, Parietti-Winkler et al. (2006) found a poorer postural performance of patients before surgery compared to that found 3 months post-operative. They assume that this reflects an inappropriate central compensation of the tonic imbalance of the descending vestibulo-spinal influences during tumor growth.

Furthermore, small VSs encroaching on an otherwise intact vestibular nerve are likely to cause vertigo attacks which provoke particular discomfort in patients. In our study, almost $50 \%$ of patients in group 1 suffered from vertigo attacks as compared to only $22 \%$ in group 2 , whereas there was little difference in the rate of continuous unsteadiness/dizziness. The number of patients suffering from these particularly disabling vertigo attacks dropped by almost $40 \%$ after treatment. Hence, the improvement in quality of life after radio-/microsurgery may be due to central compensation

\section{REFERENCES}

Adler, J. R. Jr., Chang, S. D., Murphy, M. J., Doty, J., Geis, P., and Hancock, S. L. (1997). The Cyberknife: a frameless robotic system for radiosurgery. Stereotact. Funct. Neurosurg. 69, 124-128.

Brandt, T. (2000). Management of vestibular disorders. J. Neurol. 247, 491-499.

Curthoys, I. S., and Halmagyi, G. M. (1999). Vestibular compensation. Adv. Otorhinolaryngol. 55, 82-110.

Darrouzet, V., Martel, J., Enée, V., Bébéar, J. P., and Guérin, J. (2004). Vestibular schwannoma surgery outcomes: our multidisciplinary experience in 400 cases over 17 years. Laryngoscope 114, 681-688.

Delbrouck, C., Hassid, S., Massager, N., Choufani, G., David, P., Devriendt, D., and Levivier, M. (2003). Preservation of hearing in vestibular schwannomas treated by radiosurgery using Leksell gamma knife: preliminary report of a prospective Belgian clinical study. Acta Otorhinolaryngol. Belg. 57, 197-204.

Driscoll, C. L., Lynn, S. G., Harner, S. G., Beatty, C. W., and Atkinson, E.
J. (1998). Preoperative identification of patients at risk of developing persistent dysequilibrium after acoustic neuroma removal. Am. J. Otol. 19, 491-495.

El-Kashlan, H. K., Shepard, N. T., Arts, H. A., and Telian, S. A. (1998). Disability from vestibular symptoms after acoustic neuroma resection. Am. J. Otol. 19, 104-111.

Hayhurst, C., Dhir, J., and Dias, P. S. (2005). Stereotactic radiosurgery and vestibular schwannoma: hydrocephalus associated with the development of a secondary arachnoid cyst: a report of two cases and review of the literature. Br. J. Neurosurg. 19, 178-181.

Heerma, H., Braun, V., and Richter, H. P. (2000). Einfluss der mikroneurochirugischen Operation bei Akustikusneurinom auf dessen Symptome Schwindel und Tinnitus.

Hempel, J. M., Hempel, E., Wowra, B., Schichor, C., Muacevic, A., and Riederer, A. (2006). Functional outcome after gamma knife treatment in vestibular schwannoma. Eur. Arch. Otorhinolaryngol. 263, 714-718.

Humphriss, R. L., Baguley, D. M., and Moffat, D. A. (2003). Change in HNO 5, 372-377.

in the setting of a stable vestibular function as well as to a reduction of vertigo attacks.

\section{CONCLUSION}

Whereas loss of vestibular function in VS tends to be more severe in large tumors, tumor size does not predict loss of quality of life as assessed by DHI. This may be explained by central compensation of vestibular deficits in long-standing large tumors. Furthermore, vertigo attacks seem to be more disruptive of quality of life than permanent unsteadiness/dizziness. Hence, even patients with small VS should be recommended for treatment if they suffer from disabling vertigo attacks.

The treatment modality (radio- vs microsurgery) should be chosen on the basis of individual patient characteristics. Important determinants are tumor size, diagnostic certainty, and patient preference. Furthermore, the results of our study suggest that the method of treatment does not influence the long-term (i.e., follow-up 2) outcome concerning vestibular function and quality of life. However, deterioration of hearing is more pronounced after micro- than after radiosurgery.

Shortcomings of this trial are the relatively small number of patients included and the selection bias regarding the choice of treatment modality. In order to further investigate hearing and vestibular function after radio- and microsurgery in VS and to evaluate whether maintenance of vestibular function proves to be advantageous for quality of life in the long course, we suggest further follow-ups after two and more years post-treatment in a larger group of patients who are more homogenous concerning tumor size.

dizziness handicap after vestibular schwannoma excision. Otol. Neurotol. 24, 661-665.

Inoue, Y., Ogawa, K., and Kanzaki, J. (2001). Quality of life of vestibular schwannoma patients after surgery. Acta Otolaryngol. 121, 59-61.

Jongkees, L. B., Maas, J., and Philipszoon, A. (1962). Clinical electronystagmography: a detailed study of electronystagmography in 341 patients with vertigo. Pract. Otorhinolaryngol. (Basel) 24, 65-93.

Kammerlind, A. S., Ledin, T. E., Skargren, E. I., and Odkvist, L. M. (2005). Long-term follow-up after acute unilateral vestibular loss and comparison between subjects with and without remaining symptoms. Acta Otolaryngol. 125, 946-953.

Leksell, L. (1983). Stereotactic radiosurgery. J. Neurol. Neurosurg. Psychiatr. 46, 797-803.

Lynn, S. G., Driscoll, C. L., Harner, S. G., Beatty, C. W., and Atkinson, E. J. (1999). Assessment of dysequilibrium after acoustic neuroma removal. Am. J. Otol. 20, 484-494.

Mack, A., Wolff, R., Weltz, D., Mack, G., Jess, A., Heck, B., Czempiel,
H., Kreiner, H. J., Wowra, B., Böttcher, H., and Seiffert, V. (2002). Experimentally determined threedimensional dose distributions in small complex targets. J. Neurosurg. 97, 551-555.

Myrseth, E. Møller, P., Pedersen, P. H., and Lund-Johansen, M. (2009). Vestibular schwannoma: surgery or gamma knife radiosurgery? A prospective, nonrandomized study. Neurosurgery 64 654-661.

Parietti-Winkler, C., Gauchard, G. C. Simon, C., and Perrin, P. P. (2006). Sensorimotor postural rearrangement after unilateral vestibular deafferentation in patients with acoustic neuroma. Neurosci. Res. 55, 171-181.

Parving, A., Tos, M., Thomsen, J., Møller, H., and Buchwald, C. (1992). Some aspects of life quality after surgery for acoustic neuroma. Arch. Otolaryngol. Head Neck Surg. 118, 1061-1064.

Pérez, N., Martin, E., and Garcia-Tapia, R. (2003). Dizziness: relating the severity of vertigo to the degree of handicap by measuring vestibular impairment. Otolaryngol. Head Neck Surg. 128, 372-381. 
Pollock, B. E., Driscoll, C. L., Foote, R. L., Link, M. J., Gorman, D. A., Bauch, C. D., Mandrekar, J. N., Krecke, K. N., and Johnson, C. H. (2006). Patient outcomes after vestibular schwannoma management: a prospective comparison of microsurgical resection and stereotactic radiosurgery. Neurosurgery 59, 77-85.

Pyykkö, I., Aalto, H., Starck, J., and Ishizaki, H. (1995). Postural control in Menière's disease and acoustic neurinoma when studied on a linearly oscillating platform. Acta Otolaryngol. Suppl. 520, 19-21.

Smith, P. F., and Darlington, C. L. (1991). Neurochemical mechanisms of recovery from peripheral vestibular lesions (vestibular compensation). Brain Res. Rev. 16, 117-133.

Sughrue, M. E., Yang, I., Han, S. J., Aranda, D., Kane, A. J., Amoils, M., Smith, Z. A., and Parsa, A. T. (2009). Non-audiofacial morbidity after Gamma Knife surgery for vestibular schwannoma. Neurosurg. Focus 27, E4.

Tonn, J. C., Schlake, H. P., Goldbrunner, R., Milewski, C., Helms, J., and Roosen, K. (2000). Acoustic neuroma surgery as an interdisciplinary approach: a neurosurgical series of 508 patients. J. Neurol. Neurosurg. Psychiatr. 69, 161-166.
Tos, M., Thomsen, J., and Charabi, S. (1992). Incidence of acoustic neuromas. Ear Nose Throat J. 71, 391-393.

Conflict of Interest Statement: The authors declare that the research was conducted in the absence of any commercial or financial relationships that could be construed as a potential conflict of interest.

Received: 29 June 2011; paper pending published: 26 July 2011; accepted: 09 August 2011; published online: 30 August 2011.

Citation: Wagner JN, Glaser M, Wowra B, Muacevic A, Goldbrunner R, Cnyrim
C, Tonn J-C and Strupp M (2011) Vestibular function and quality of life in vestibular schwannoma: does size matter? Front. Neur. 2:55. doi: 10.3389/fneur.2011.00055

This article was submitted to Frontiers in Neuro-otology, a specialty of Frontiers in Neurology.

Copyright (c) 2011 Wagner, Glaser, Wowra, Muacevic, Goldbrunner, Cnyrim, Tonn and Strupp. This is an open-access article subject to a nonexclusive license between the authors and Frontiers Media SA, which permits use, distribution and reproduction in other forums, provided the original authors and source are credited and other Frontiers conditions are complied with. 